\title{
Moisture damage and childhood asthma: a population-based incident case-control study
}

\author{
J. Pekkanen**\#, A. Hyvärinen*, U. Haverinen-Shaughnessy*, M. Korppi ${ }^{\top}$, \\ T. Putus* and A. Nevalainen*
}

ABSTRACT: Most previous studies on the association between moisture damage and asthma have been cross-sectional and relied on self-reported exposure and health. The present authors studied the association by carrying out careful home inspections among new, clinically determined cases of asthma and controls.

New cases of asthma aged 12-84 months $(n=121)$ were recruited prospectively and matched for year of birth, sex and living area with two randomly selected population controls $(n=241)$. Trained engineers visited all homes. Both cases and controls had lived $\geqslant 75 \%$ of their lifetime or the past 2 yrs in their current home.

Risk of asthma increased with severity of moisture damage and presence of visible mould in the main living quarters but not in other areas of the house. Cases more often had damage in their bedroom. Associations were comparable for atopic and nonatopic asthma and for children aged $>\mathbf{3 0}$ months or $\leqslant \mathbf{3 0}$ months.

The present results, using standardised assessment of exposure and asthma, suggest that moisture damage and mould growth in the main living quarters are associated with the development of asthma in early childhood.

KEYWORDS: Asthma, atopy, environmental health, epidemiology, indoor, moulds

A large number of studies have observed an association between home dampness and respiratory symptoms such as wheezing, coughing and asthma [1, 2]. As concluded in the recent US Institute of Medicine report on indoor dampness and health, there is sufficient evidence regarding the exacerbation of asthma symptoms, but whether exposure to dampness also causes development of asthma is still unclear [2]. Most studies have been cross-sectional and relied on self-reported exposure or health or both. However, occupants' reports on dampness or mould growth are often inaccurate [3-5]. The parents of asthmatic children may systematically over-report home dampness and thereby create an artificial association between home dampness and asthma [6], or the presence of dampness and mould in the home may lead to over-reporting of symptoms [7]. Therefore, although it is acknowledged that home dampness exacerbates existing asthma, it is not known whether it is also associated with development of asthma [2].

A few studies on asthma or asthma-related symptoms among children using site visits or other standardised measurements of home dampness or mould exposure have recently been conducted. Most of these studies [5, 8-11] have been based on birth cohort studies that have followed the children only to the age of 1 or 2 yrs, which makes them difficult to interpret given the transient nature of asthma-related symptoms in early age [12, 13]. A case-control study of prevalent asthma reported an association between self-reported, but not observed, damp and mould [4]. A recent cohort study using selfreported exposure reported an association between incident asthma and mould odour [14]. There are no studies on the specific association of home dampness with atopic versus nonatopic asthma.

The present authors therefore conducted a casecontrol study of newly diagnosed childhood asthma, using randomly selected populationbased controls. The severity and location of moisture damage were assessed during a detailed home visit by trained civil engineers. In addition to overall analyses, atopic versus nonatopic asthmatics and those with early- versus

\section{AFFILIATIONS}

*Dept of Environmental Health, National Public Health Institute,

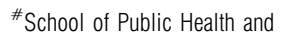
Clinical Nutrition, University of Kuopio, and

"Dept of Paediatrics, Kuopio University Hospital, Kuopio, Finland.

CORRESPONDENCE

J. Pekkanen

Dept of Environmental Health National Public Health Institute P.0.Box 95

70701 Kuopio

Finland

Fax: 35817201265

E-mail: juha.pekkanen@ktl.fi

Received:

March 222006

Accepted after revision:

November 022006

SUPPORT STATEMENT

This study was carried out in cooperation with the Finnish Asthma and Allergy Federation (Helsinki, Finland), with funding from Rahaautomaattiyhdistys (Espoo, Finland), the Yrjö Jahnsson Foundation and Päivikki and Sakari Sohlberg's Foundation (both Helsinki).

STATEMENT OF INTEREST None declared.

European Respiratory Journal Print ISSN 0903-1936 Online ISSN 1399-3003 
late-onset asthma were analysed separately, as atopic, lateonset asthma is more likely to persist $[12,13]$.

\section{METHODS \\ Study subjects}

New cases of asthma were prospectively collected at the Dept of Paediatrics, Kuopio University Hospital (Kuopio, Finland) [15]. In Finland, a paediatrician is required to diagnose asthma in children. At the time of the study, Kuopio University Hospital was the only one providing paediatric care for the study area, as there were no private or primary care paediatricians in the area. Children aged 12-84 months who were referred to the hospital after at least the second attack of wheezing, or who were diagnosed as asthmatics at the hospital's allergy unit, were eligible as cases. The earlier attack(s) of asthma also had to be diagnosed by a doctor and must not have occurred $>1$ yr previously. The children were not allowed to have an earlier asthma diagnosis or have ever been on regular medication because of asthma.

The hospital collected eligible cases and the study centre randomly drew two controls for each case from the Finnish Population Register. Both cases and controls were required to have lived $\geqslant 2$ yrs or $\geqslant 75 \%$ of their lifetime in their current home. Controls reporting asthma were excluded. Controls were individually matched for year of birth, sex and municipality with the case. Questionnaires on health and risk factors of asthma were mailed to both cases and controls before the home visit, and were checked and collected back during the study visit.

The original sample size calculation used an estimated proportion of exposure of $30 \%$ among controls and an odds ratio of $1.8(\alpha=0.05, \beta=0.8)$, resulting in a requirement for 150 cases and 300 controls. Recruitment lasted from October 3, 1996 to May 9, 2000. By that date, 172 cases and 391 controls had been invited to take part in the study. A total of $49(28.5 \%)$ cases did not fulfil the selection criteria and two (1.2\%) refused to participate. The corresponding numbers for controls were $102(26 \%)$ and $47(12 \%)$, respectively. Finally, 121 (70\%) cases and $242(62 \%)$ controls participated in the study and had a home visit. However, due to technical problems, building investigation data was only available for 241 controls.

Specific immunoglobulin (Ig)E results were available for 102 $(84 \%)$ cases but for only 103 controls. Therefore, IgE results for cases were used only to differentiate atopic and nonatopic asthmatics. Atopy was defined as specific $\mathrm{IgE}>0.35 \mathrm{IU} \cdot \mathrm{mL}^{-1}$ against any of the 14 inhalant and food allergens tested (Phadiatop Combi; Pharmacia, Uppsala, Sweden) [16].

The study protocol was approved by the Joint Ethics Committee for Human Research at the University of Kuopio (Kuopio, Finland) and the Kuopio University Hospital (Kuopio).

\section{Assessment of exposure}

The home inspections were carried out according to a standard protocol [17]. The inspectors were two trained building engineers, both having several years' experience with the protocol. In 15 residences, the building inspection protocol was carried out by both engineers at separate times. The average kappa value between the moisture-damage observations of the two engineers was 0.41 [3]. The residences were inspected for signs of excess moisture, e.g. water leaks or condensation, moisture stains, visible mould, colour changes on building materials and detached surface materials. Visual observations of excess moisture were verified using a surface moisture recorder (BD2 or BS2; Doser, Füssen, Germany).

The information recorded during the visit using pre-designed checklists was focused on the whole house, with the exception that occurrence of damage in the child's bedroom was also recorded separately. Information included general building characteristics, estimation of occurrence and area of moisture damage, presence of mould growth and odour, and estimated "need for repair" using a 6-point scale [17]. Briefly, classes 0 and 1 meant damage with no need for repair or only cosmetic repair, class 2 meant repair of surface materials needed, class 3 meant repair of structural component needed, and classes 4 and 5 meant more extensive repair needed.

In addition, each individual area of damage was documented in detail using a free format, including information on location and area of damage, observations of visible mould [18], and need for repair [17]. Location of damage was divided into four areas: main living quarters; kitchen; bathroom; and other areas. Main living quarters were defined as bedrooms, living rooms, and main hallways connecting these rooms. Bathroom included toilets, bathrooms/shower and sauna. Other interior spaces included basement, attic, closets and storage space, if inside the home.

To characterise these four areas of the house, two classifications for moisture damage were defined a priori. Severity of damage was classified as follows: "no damage" was defined as need for repair classes 0 or 1 ; and "major damage" as need for repair class 2 and total area of damage $\geqslant 1 \mathrm{~m}^{2}$, need for repair class 3 and area $\geqslant 0.1 \mathrm{~m}^{2}$, or need for repair classes 4 or 5 . Other damage in the area was defined as "minor damage". Maximum damage was defined based on the need for repair classification of the most severe damage in the given area.

\section{Statistical analyses}

The primary analyses compared all cases $(n=121)$ with all controls $(n=241)$. Due to missing data mainly on the confounders, the number of subjects in the multivariate models ranged 316-324. In stratified analyses, atopic cases $(n=62)$ were compared with their controls $(n=124)$, and nonatopic cases $(n=40)$ with their own controls $(n=80)$. In addition, cases aged $\leqslant 30$ months $(n=70)$ were compared with their controls $(n=139)$ and cases aged $>30$ months $(n=51)$ were compared with their controls $(n=102)$. Owing to missing data, the number of subjects in the multivariate models ranged 164-165 among atopic cases and their controls, 104106 among nonatopic cases and their controls, 189-190 among those aged $\leqslant 30$ months and 133-135 among those aged $>30$ months.

All analyses between moisture damage and risk of asthma were performed using conditional logistic regression. Confounders for the multivariate models were selected mainly based on a $>10 \%$ change in the estimate for moisture damage in the main living area but the chosen confounder model was also checked with other outcomes. Finally, all multivariate analyses were adjusted for parental asthma, father's education, 
number of siblings, having pets indoors currently and day-care attendance aged $<12$ months. Smoking by the mother during or after pregnancy or smoking by other people at home did not confound the associations. The statistical significance of the difference in the odds ratios in the subgroups by atopy and age was calculated by dividing their difference by the variance of the difference assuming no covariance, i.e. the square root of the sum of the standard errors squared.

\section{RESULTS}

Cases were aged 12-84 months and controls 12-92 months (table 1). There were no major differences in parental education, exposure to tobacco smoke, day-care attendance aged $<12$ months and living on a farm, but asthmatic children had fewer pets currently and more asthmatic parents and tended to have fewer siblings. There were no major differences in income or in breastfeeding (data not shown).

There were no statistically significant differences between the characteristics of the homes of cases and controls. However, the homes of asthmatic children tended less often to have a basement, a flat roof and natural ventilation, but more often to have condensation on windows, humidifiers and additional heating (table 1).

\section{TABLE 1 Characteristics of cases and controls}

\begin{tabular}{|c|c|c|}
\hline & Controls & Cases \\
\hline Subjects $\mathrm{n}^{\#}$ & 241 & 121 \\
\hline Male \% & 66.7 & 65.8 \\
\hline Age yrs & 3.23 & 2.91 \\
\hline Father's education yrs & 13.0 & 13.3 \\
\hline Mother's education yrs & 14.2 & 14.1 \\
\hline Parental asthma \% & 9.1 & 20.7 \\
\hline Current smoking at home \% & 31.0 & 27.5 \\
\hline \multicolumn{3}{|l|}{ Number of siblings $\%$} \\
\hline 0 & 21.2 & 12.9 \\
\hline 1 & 39.8 & 56.0 \\
\hline $2+$ & 38.8 & 31.1 \\
\hline No day care $<1$ yr $\%$ & 98.3 & 95.0 \\
\hline Child has lived on a farm \% & 15.5 & 14.2 \\
\hline Pets currently \% & 48.3 & 28.1 \\
\hline \multicolumn{3}{|l|}{ Building characteristics } \\
\hline Single family/row house \% & 75.9 & 74.4 \\
\hline Basement \% & 17.5 & 11.8 \\
\hline Timber/log frame \% & 57.3 & 57.0 \\
\hline Flat roof $\%$ & 14.9 & 8.3 \\
\hline Renovated \% & 79.2 & 79.0 \\
\hline Natural ventilation \% & 37.8 & 30.6 \\
\hline Condensation on windows \% & 33.7 & 40.4 \\
\hline Use of humidifiers $\%$ & 7.5 & 12.7 \\
\hline Use of additional heating \% & 33.2 & 36.4 \\
\hline Age of the building yrs & 24.8 & 26.7 \\
\hline Size of the building $\mathrm{m}^{2}$ & 105.4 & 105.4 \\
\hline
\end{tabular}

Data are presented as mean, unless otherwise stated. \#: The number of observations with nonmissing data on different characteristics ranged 220-241 among controls and 116-121 among cases.
Initially, moisture-damage variables characterising the whole house were analysed (table 2). Cases tended less often to have any moisture damage. This difference persisted when houses with a basement were excluded from the analyses (data not shown). The overall area of damage in the residence tended to be larger among cases, and there was a tendency for the asthma cases to have more visible mould and mould odour in their homes. Past, but not current, reports of mould odour by the occupants was also more prevalent among the cases (data not shown).

Second, all observed damage sites, coded by their location, were analysed. Moisture damage and visible mould in the main living quarters was associated with increased risk of asthma (table 3). There were no significant associations for all the other areas.

When the damage observations in the main living quarters of the house and in the child's bedroom were analysed in more detail (table 4), there appeared to be a dose-dependent increase in the risk of asthma with severity of moisture damage and with maximum severity of the damage. Cases also tended to have larger damage sites and more mould odour.

The associations of moisture damage in the main living area or in the child's bedroom with asthma were mostly very similar for nonatopic and for atopic asthma, and for children aged $\leqslant 30$ months or $>30$ months (table 5). However, for visible mould the association was significantly $(\mathrm{p}<0.05)$ stronger with atopic than with nonatopic asthma.

\section{DISCUSSION}

In the present population-based case-control study, an association was observed between the risk of developing

\begin{tabular}{|c|c|c|c|}
\hline \multirow[t]{2}{*}{ TABLE 2} & \multicolumn{3}{|c|}{$\begin{array}{l}\text { Moisture-damage characteristics of the whole } \\
\text { home and their multivariate adjusted } \\
\text { associations with asthma }\end{array}$} \\
\hline & & Prevalence & Cases versus controls \\
\hline \multirow{2}{*}{\multicolumn{4}{|c|}{$\begin{array}{l}\text { Any or suspected } \\
\text { moisture damage }\end{array}$}} \\
\hline & & & \\
\hline \multicolumn{2}{|c|}{ No } & $49(13.6)$ & 1 \\
\hline \multicolumn{2}{|l|}{ Yes } & $310(86.4)$ & $0.63(0.28-1.45)$ \\
\hline \multicolumn{4}{|c|}{ Need for repair } \\
\hline \multicolumn{2}{|c|}{1} & $66(18.4)$ & 1 \\
\hline \multicolumn{2}{|l|}{2} & $177(49.3)$ & $0.66(0.30-1.46)$ \\
\hline \multicolumn{2}{|l|}{$3+$} & $116(32.4)$ & $0.90(0.40-2.00)$ \\
\hline \multicolumn{2}{|c|}{ Area of damage ${ }^{\#} \mathbf{m}^{2}$} & 352 (3.33) & $1.01^{+}(0.98-1.05)$ \\
\hline \multicolumn{4}{|c|}{ Visible mould" } \\
\hline \multicolumn{2}{|c|}{ No } & $184(51.3)$ & 1 \\
\hline \multicolumn{2}{|c|}{ Yes } & $175(48.7)$ & $1.24(0.73-2.11)$ \\
\hline \multicolumn{4}{|c|}{ Mould odour" } \\
\hline \multicolumn{2}{|l|}{ No } & 331 (92.2) & 1 \\
\hline \multicolumn{2}{|l|}{ Some } & $19(5.3)$ & $1.35(0.42-4.36)$ \\
\hline \multicolumn{2}{|l|}{ Clear } & $9(2.5)$ & $4.12(0.65-26.01)$ \\
\hline
\end{tabular}

Data are presented as $\mathrm{n}(\%)$ or odds ratio (95\% confidence interval), unless otherwise stated. ${ }^{\#}$ : mean area of damage; ": inspector's observations; ${ }^{+}$: for a $1 \mathrm{~m}^{2}$ change in area of damage. 


\begin{tabular}{|c|c|c|c|}
\hline \multirow[t]{2}{*}{ TABLE 3} & \multicolumn{3}{|c|}{$\begin{array}{l}\text { Moisture-damage characteristics in different } \\
\text { areas of the home and their multivariate adjusted } \\
\text { association with asthma }\end{array}$} \\
\hline & & Prevalence & Cases versus controls \\
\hline \multicolumn{4}{|c|}{ Main living area } \\
\hline \multicolumn{4}{|c|}{ Severity of damage } \\
\hline No & & 251 (69.5) & 1 \\
\hline Minor or $\mathrm{m}$ & lajor & $110(30.4)$ & $2.24(1.25-4.01)$ \\
\hline \multicolumn{4}{|c|}{ Visible mould } \\
\hline No & & 327 (90.6) & 1 \\
\hline Yes & & $34(9.4)$ & $2.59(1.15-5.85)$ \\
\hline \multicolumn{4}{|c|}{ Kitchen } \\
\hline \multicolumn{4}{|c|}{ Severity of damage } \\
\hline No & & $256(70.9)$ & 1 \\
\hline Minor or $\mathrm{m}$ & najor & $105(29.1)$ & $1.41(0.80-2.47)$ \\
\hline \multicolumn{4}{|c|}{ Visible mould } \\
\hline No & & $270(74.8)$ & 1 \\
\hline Yes & & $91(25.2)$ & $1.13(0.63-2.04)$ \\
\hline \multicolumn{4}{|c|}{ Bathroom } \\
\hline \multicolumn{4}{|c|}{ Severity of damage } \\
\hline No & & $102(28.3)$ & 1 \\
\hline Minor or $\mathrm{m}$ & ajor & $122(71.8)$ & $0.70(0.39-1.25)$ \\
\hline \multicolumn{4}{|c|}{ Visible mould } \\
\hline No & & $268(74.2)$ & 1 \\
\hline Yes & & $93(25.7)$ & $0.81(0.44-1.49)$ \\
\hline \multicolumn{4}{|c|}{ Other interior spaces } \\
\hline \multicolumn{4}{|c|}{ Severity of damage } \\
\hline No & & $275(76.2)$ & 1 \\
\hline Minor or $\mathrm{m}$ & ajor & $86(23.8)$ & $0.77(0.40-1.46)$ \\
\hline \multicolumn{4}{|c|}{ Visible mould } \\
\hline No & & $319(88.1)$ & 1 \\
\hline Yes & & $14(11.9)$ & $0.86(0.37-2.00)$ \\
\hline
\end{tabular}

Data are presented as $n(\%)$ or odds ratio (95\% confidence interval).

new asthma among children aged 1-6 yrs and moisture damage at home. Only moisture damage in the main living quarters of the home was associated with asthma. Trained engineers visited all homes to assess the severity and location of moisture damage and mould growth. The present results suggest that moisture and mould problems at home may increase the incidence of new asthma in early childhood.

Previous studies have usually found similar or somewhat lower odds ratios for childhood asthma [2] than the present study. These studies have, however, mostly been crosssectional and have used data on self-reported exposure. A few studies have also used objective measurements of home dampness or moulds. In a case-control study [4], an association between chronic respiratory symptoms and asthma and self-reported dampness, but not dampness observed by an inspector, was observed. A crude odds ratio of 2.6 was reported between both self-reported and confirmed moisture problems and repeat bronchial obstruction by the age of $2 \mathrm{yrs}$, but in adjusted analyses confirmed moisture problems were a stronger predictor [5]. In a cross-sectional study, there was a positive association of mould spore counts in dust with atopic sensitisation but not with asthma [8]. Three recent birth cohort

\begin{tabular}{|c|c|c|c|}
\hline \multirow[t]{2}{*}{ TABLE 4} & \multicolumn{3}{|c|}{$\begin{array}{l}\text { Moisture-damage characteristics in the main } \\
\text { living area and in the child's bedroom and their } \\
\text { multivariate adjusted association with asthma }\end{array}$} \\
\hline & & Prevalence & Cases versus controls \\
\hline \multicolumn{4}{|c|}{ Main living area } \\
\hline \multicolumn{4}{|c|}{ Severity of damage } \\
\hline No & & 251 (69.5) & 1 \\
\hline Minor & & 72 (19.9) & $2.11(1.06-4.21)$ \\
\hline Major & & $38(10.5)$ & $2.46(1.09-5.55)$ \\
\hline \multicolumn{4}{|c|}{ Maximum severity } \\
\hline 0 & & $177(49.2)$ & 1 \\
\hline $1-2$ & & $143(39.7)$ & $2.75(1.40-5.40)$ \\
\hline $2+$ & & $40(11.1)$ & $4.04(1.60-10.20)$ \\
\hline Area of dar & age $\mathrm{m}^{2}$ & $357\left(0.38^{\bullet}\right)$ & $1.36^{+}(0.91-2.03)$ \\
\hline \multicolumn{4}{|c|}{ Mould growth } \\
\hline No & & $327(90.6)$ & 1 \\
\hline Mould sp & & $14(3.9)$ & $4.01(1.12-14.32)$ \\
\hline Visible $m$ & & $20(5.5)$ & $1.95(0.69-5.47)$ \\
\hline \multicolumn{4}{|c|}{ Mould odour } \\
\hline No & & $353(97.8)$ & 1 \\
\hline Yes & & $8(2.2)$ & $2.96(0.62-14.19)$ \\
\hline \multicolumn{4}{|c|}{ Damage in child's bedroom ${ }^{\#}$} \\
\hline No & & $300(83.8)$ & 1 \\
\hline Yes & & $58(16.2)$ & $1.97(1.00-3.90)$ \\
\hline Area of dar & age $\mathrm{m}^{2}$ & $352\left(0.04^{\circ}\right)$ & $1.52^{+}(0.63-3.70)$ \\
\hline
\end{tabular}

Data are presented as $n$ (\%) or odds ratio (95\% confidence interval), unless otherwise stated. ${ }^{\#}$ : damage in the child's bedroom was recorded separately during the visit. In addition, all observed damage was classified after the visit as occurring in any of the main living areas. ${ }^{\top}$ : mean area of damage; ${ }^{+}$: for a $1 \mathrm{~m}^{2}$ change in area of damage.

studies have reported positive associations between measured levels of fungi and wheezing $[9,11]$ and lower respiratory tract illness [10] in the first 12 months of life. A recent cohort study using self-reported exposure reported an association between incident asthma and mould odour, but not other indicators of moisture damage [14]. There are no previous studies on the specific association of home dampness with atopic versus nonatopic asthma.

In the present study, a detailed examination of all the homes was carried out by a civil engineer [17]. This allowed an analysis of the effect of location and extent of damage on the risk of asthma to be carried out. It was observed that only moisture damage in the main living areas or in the child's bedroom was associated with asthma. This issue has rarely been considered previously [4], although it is evident that the child spends most of his/her time in these rooms, which means that the exposure times are remarkably longer than in other locations. Thus, moisture damage in the basement or in the attic is likely to contribute much less to the exposure of the child. Children may also be exposed less to moisture damage in the kitchen and especially in bathrooms, as the exposure times are shorter.

It is worth noting that moisture damage, especially in the bathroom, may frequently be due to excessive use of water. 


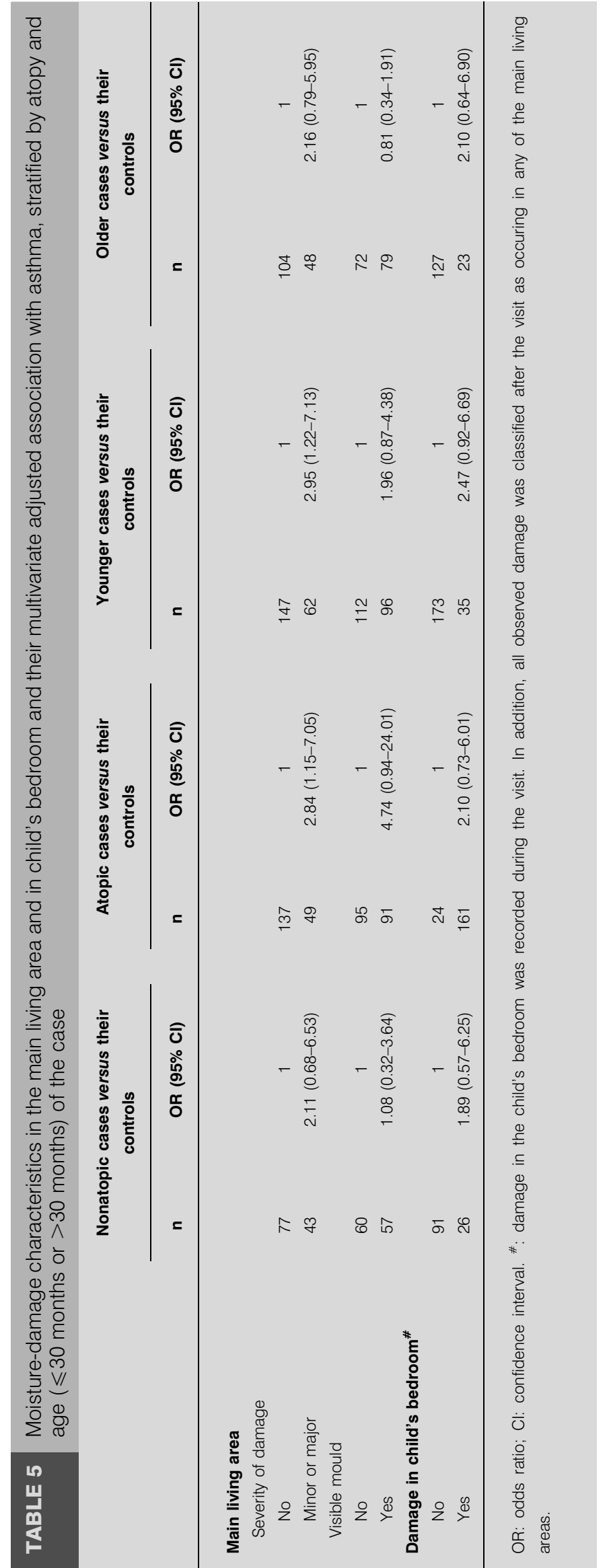

This may lead to different conditions for microbial growth and subsequent emissions [2]. Also, kitchen and bathroom facilities are usually better ventilated and under negative pressure compared with the living area. The importance of the location of the moisture damage clearly needs further study but the present results suggest that it is one of the major determinants of the health effects of moisture damage $[18,19]$.

Home inspection gives a good indication of long-term exposure. In addition, focusing on the building, which is the source of the exposure, helps to understand the whole complex exposure situation and its determinants. In contrast, sampling and culturing airborne mold spores has poor reproducibility owing to large variations in time and space [20]. The method also detects only viable fungi [1]. Nonculture-based methods, such as measuring markers of microbes from settled dust [21] or using DNA-based methods such as quantitative PCR [22], appear more promising. However, the pathophysiological mechanism linking home dampness and asthma is currently unknown [1], and therefore it is unclear which microbes or components of microbes to measure. The toxicity of different microbes is also modified by differences in the materials upon which they live and in their growth conditions indoors [23, 24]. Therefore, in addition to markers of specific microbes, building investigations, as in the present study, are needed.

Several possible mechanisms have been suggested for the observed associations between home dampness or indoor mould and asthma. Moulds can induce the production of specific IgE antibodies, which are related to severity of asthma [25]. However, the association between moisture damage or mould growth and $\mathrm{IgE}$ production is very weak [26]. Therefore, non-IgE-mediated mechanisms are more likely. Components of fungal cell walls, such as $\beta(1-3)$-glucans [27], or volatile organic compounds, may act as irritants in the airways. Fungi and bacteria produce microbial toxins in moisture damage situations [28-31], which deserve attention owing to the acute toxicity of these products [32]. The evidence on the role of microbial metabolites in the causation of asthma is, however, very limited or nonexistent [1]. For instance, the observed levels of volatile organic compounds in damaged homes are usually considerably lower than the levels that would cause irritation [33]. Given the lack of evidence for IgEmediated sensitisation $[1,26]$ and the low indoor levels of most measured irritants in moisture-damaged buildings [34], it is tempting to speculate that the underlying mechanism involves some, as yet unknown, immunological reactions. Unfortunately, due to the low number of specific IgE results among the controls, the present authors were not able to study the association between moisture damage and development of atopy or the potential effect modification by atopy.

Home dampness has previously been linked with house dust mites at home. However, in Finnish homes, house dust mites occur quite infrequently and in low numbers, mainly because indoor air relative humidity is well under $50 \%$ for most of the year. Also, in a previous study, dust mites occurred in beds and padded furniture in similar prevalence, regardless of whether moisture and mould problems were observed in buildings [35]. As part of the present study, house dust mites were studied using the Acarex test in the beds of 50 asthmatics and 46 nonasthmatics. Mites were observed equally frequently 
in the beds of asthmatics (34\%) and nonasthmatics (33\%; unpublished data). Hence, house dust mites are not likely to confound the observed association between home dampness and asthma.

The present design has limitations. The home visits were made after the child was recruited to the study, i.e. only after the asthma was diagnosed. However, the home inspection provides a very good reflection of the moisture history of the house in the preceding years. The recruited children, especially the younger ones, were required to have lived practically all their life in the inspected home. Also, the development of moisture damage is often slow in cold climates (several months to years). Therefore, the present design resembles as closely as was practically possible a prospective birth cohort study.

Although the engineers making the home visits were blinded to the asthma status of the child, it is difficult to maintain this blinding during the home visit. Therefore, it could be suspected that engineers would find more moisture problems in the homes of asthmatics. However, in the present study, the engineers found more moisture problems in total in the homes of the controls, which speaks against this possibility, although the homes of asthmatics had more damage observed only in the living areas. The pre-designed checklist used during the visit also gives equal weight to all interior spaces of the house.

In an effort to cover the lifetime history of moisture damage, the current study focused on young children, among whom asthma is often of a transient nature $[12,13]$. In the present study, new cases of asthma were recruited from a hospital clinic by a paediatrician and were required to have had at least two doctor-diagnosed attacks of wheezing. Therefore, despite their young age, most of the children in the present study are likely to have persistent asthma. The association between moisture damage and asthma was explored separately by age ( $\leqslant 30$ months or $>30$ months) and atopy, as wheezing in the first 3 yrs of life and among nonatopics has been reported to be transient more often than wheezing in later life and among atopics $[12,13]$. The associations were found to be comparable among atopic and nonatopic asthmatics and among those with early and late onset of the disease, further suggesting that moisture damage at home not only exacerbates asthma symptoms, but is also involved in the development of persistent asthma.

In conclusion, the present results demonstrate the importance of the location of the moisture damage and suggest that moisture damage at home not only exacerbates asthma symptoms, but is also involved in the development of persistent asthma. Although the exact mechanisms linking moisture damage and mould growth with the risk of asthma are unknown, the present results underline the urgent need to improve building designs, construction and maintenance practices in order to prevent moisture damage and consequent risks to occupant health.

\section{ACKNOWLEDGEMENTS}

The authors wish to thank J. Halla-aho and J. Koivisto for the building investigations, P. Tiittanen for statistical assistance, and the study participants and personnel of Dept of Paediatrics, Kuopio University Hospital (Kuopio, Finland) and the National Public Health Institute (Helsinki, Finland).

\section{REFERENCES}

1 Douwes J, Pearce N. Invited commentary: is indoor mold exposure a risk factor for asthma? Am J Epidemiol 2003; 158: 203-206.

2 Institute of Medicine committee on damp indoor spaces and health. Damp Indoor Spaces and Health. Washington, The National Academies Press, 2004.

3 Haverinen-Shaughnessy U, Hyvärinen A, Pekkanen J, et al. Occurrence and characteristics of moisture damage in residential buildings as a function of occupant and engineer observations. Indoor Built Environ 2005; 14: 133-140.

4 Verhoeff AP, van Strien RT, van Wijnen JH, Brunekreef B. Damp housing and childhood respiratory symptoms: the role of sensitization to dust mites and molds. Am J Epidemiol 1995; 141: 103-110.

5 Nafstad P, Øie L, Mehl R, et al. Residential dampness problems and symptoms and signs of bronchial obstruction in young Norwegian children. Am J Respir Crit Care Med 1998; 157: 410-414.

6 Dales RE, Miller D, McMullen ED. Indoor air quality and health: validity and determinants of reported home dampness and moulds. Int J Epidemiol 1997; 26: 120-125.

7 Strachan DJ. Damp housing and childhood asthma: validation of reporting of symptoms. BMJ 1988; 297: 1223-1226.

8 Jacob B, Ritz B, Gehring U, et al. Indoor exposure to molds and allergic sensitisation. Environ Health Perspect 2002; 110: 647-653.

9 Gent JF, Ren P, Belanger K, et al. Levels of household mold associated with respiratory symptoms in the first year of life in a cohort at risk for asthma. Environ Health Perspect 2002; 110: A781-A786.

10 Stark PC, Burge HA, Ryan LM, Milton DK, Gold DR. Fungal levels in the home and lower respiratory tract illnesses in the first year of life. Am J Respir Crit Care Med 2003; 168: 232-237.

11 Belanger K, Beckett W, Triche E, et al. Symptoms of wheeze and persistent cough in the first year of life: associations with indoor allergens, air contaminants, and maternal history of asthma. Am J Epidemiol 2003; 158: 195-202.

12 Martinez FD, Wright AL, Taussig LM, Holberg CJ, Halonen M, Morgan WJ. Asthma and wheezing in the first six years of life. The Group Health Medical Associates. N Engl J Med 1995; 332: 133-138.

13 Korppi M, Kuikka L, Reijonen T, Remes K, JuntunenBackman K, Launiala K. Bronchial asthma and hyperreactivity after early childhood bronchiolitis or pneumonia. An 8-year follow-up study. Arch Pediatr Adolesc Med 1994; 148: 1079-1084.

14 Jaakkola JJ, Hwang BF, Jaakkola N. Home dampness and molds, parental atopy, and asthma in childhood: a six-year population-based cohort study. Environ Health Perspect 2005; 113: 357-361.

15 Korppi M, Paldanius M, Hyvarinen A, Nevalainen A, Husman T. Chlamydia pneumoniae and newly diagnosed asthma: a case-control study in 1 to 6-year-old children. Respirology 2004; 9: 255-259.

16 Paganelli R, Ansotegui IJ, Sastre J, et al. Specific IgE antibodies in the diagnosis of atopic disease. Clinical evaluation of a new in vitro test system, UniCAP, in six European allergy clinics. Allergy 1998; 53: 763-768. 
17 Nevalainen A, Partanen P, Jääskeläinen E, et al. Prevalence of moisture problems in Finnish houses. Indoor Air 1998; 7: Suppl. 4, 45-49.

18 Haverinen U, Husman T, Pekkanen J, Vahteristo M, Moschandreas D, Nevalainen A. Characteristics of moisture damage in houses and their association with selfreported symptoms of the occupants. Indoor Built Environ 2001; 10: 83-94.

19 Haverinen U, Vahteristo M, Moschandreas D, Husman T, Nevalainen A, Pekkanen J. Knowledge-based and statistically modeled relationships between residential moisture damage and occupant reported health symptoms. Atmospheric Environ 2003; 37: 577-585.

20 Hyvärinen A, Vahteristo M, Meklin T, Jantunen M, Nevalainen A, Moschandreas D. Temporal and spatial variation of fungal concentrations in indoor air. Aerosol Sci Technology 2001; 35: 688-695.

21 Sebastian A, Larsson L. Characterization of the microbial community in indoor environments: a chemical-analytical approach. Appl Environ Microbiol 2003; 69: 3103-3109.

22 Meklin T, Haughland RA, Reponen T, et al. Quantitative PCR analysis of house dust can reveal abnormal mold conditions. J Environ Monit 2004; 6: 615-620.

23 Hirvonen $M-R$, Suutari $M$, Ruotsalainen $M$, Lignell $U$, Nevalainen A. Effect of growth medium on potential of Streptomyces anulatus spores to induce inflammatory responses and cytotoxicity in RAW 264.7 macrophages. Inhal Toxicol 2001; 13: 55-68.

24 Roponen M, Toivola M, Meklin T, et al. Differences in inflammatory responses and cytotoxicity in RAW264.7 macrophages induced by Streptomyces anulatus grown on different building materials. Indoor Air 2001; 11: 179-184.

25 Zureik M, Neukirch C, Leynaert B, et al. Sensitisation to airborne moulds and severity of asthma: cross sectional study from European Community respiratory health survey. BMJ 2002; 325: 411-414.
26 Immonen J, Meklin $\mathrm{T}$, Taskinen $\mathrm{T}$, Nevalainen $\mathrm{A}$ Korppi M. Skin-prick test findings in students from moisture- and mould-damaged schools: a 3-year followup study. Pediatr Allergy Immunol 2001; 12: 87-94.

27 Douwes J, Zuidhof A, Doekes G, et al. (1-3)- $\beta$-D-Glucan and endotoxin in house dust and peak flow variability in children. Am J Respir Crit Care Med 2000; 162: 1348-1354.

28 Murtoniemi T, Nevalainen A, Suutari M, Toivola M, Komulainen $\mathrm{H}$, Hirvonen MR. Induction of cytotoxicity and production of inflammatory mediators in RAW264.7 macrophages by spores grown on six different plasterboards. Inhal Toxicol 2001; 13: 233-247.

29 Nielsen KF, Gravesen S, Nielsen PA, Andersen B, Thrane U, Frisvad JC. Production of mycotoxins on artificially and naturally infested building materials. Mycopathologia 1999; 145: 43-56.

30 Peltola J, Andersson MA, Haahtela T, et al. Toxicmetabolite-producing bacteria and fungus in an indoor environment. Appl Environ Microbiol 2001; 67: 3269-3274.

31 Andersson MA, Nikulin M, Koljalg U, et al. Bacteria, molds, and toxins in water-damaged building materials. Appl Environ Microbiol 1997; 63: 387-393.

32 Fung F, Clark RF. Health effects of mycotoxins: a toxicological overview. J Toxicol Clin Toxicol 2004; 42: 217-234.

33 Korpi A, Kasanen JP, Alarie Y, Kosma VM, Pasanen AL. Sensory irritating potency of some microbial volatile organic compounds (MVOCs) and a mixture of five MVOCs. Arch Environ Health 1999; 54: 347-352.

34 Hyvärinen A. Characterizing mold problem buildings environmental and biological monitoring. $\mathrm{PhD}$ Thesis. Publications of National Public Health Institute A8/2002. Kuopio University, Kuopio, 2002.

35 Hyvärinen A, Reponen T, Husman T, Nevalainen A. Comparison of the indoor air quality in mold problem and reference buildings in subarctic climate. Cent Eur J Public Health 2001; 3: 133-139. 